“Transfer” XV: 1-2 (2020), pp. 93-114. ISSN: 1886-554

\title{
LA FEMINIZACIÓN DEL EJERCICIO PROFESIONAL DE LA TRADUCCIÓN EDITORIAL: ENTRE LA PRECARIEDAD Y EL ENTUSIASMO
}

Carmen Francí Ventosa (ORCID: 0000-0002-0813-6880) Universidad Pontificia Comillas

\author{
"El traductor suele ser un personaje apocado. \\ Por timidez ha escogido tal ocupación, la mínima". \\ "En el orden intelectual no cabe faena más humilde". \\ José Ortega y Gasset, Miseria y esplendor de la traducción.
}

\begin{abstract}
"Este entusiasmo inducido se ha convertido en herramienta capitalista que permite mantener la velocidad productiva, esconder el conflicto bajo una máscara de motivación capaz de mantener las exigencias de la producción a menor coste". Remedios Zafra, El entusiasmo. Precariedad y trabajo creativo en la era digital
\end{abstract}

\section{Panorama general: la industria editorial y los colaboradores externos}

Faena, ocupación: así se refería Ortega y Gasset en 1937 a eso que tantos traductores y traductoras intentan ahora afrontar como una profesión. No solo porque abordan la mencionada faena $-\mathrm{u}$ ocupación- con un planteamiento profesional (en lo que se refiere a la formación y al rigor) sino porque, además, pretenden hacer de ella su medio de vida. Un porcentaje no desdeñable lo consigue ${ }^{1}$ pero muchos la compaginan con otras actividades (que tal vez sean también ocupaciones o faenas) más o menos afines. Ortega se refería al orden intelectual, pero bien podría aludir su afirmación a cuestiones más prosaicas tales como la seguridad laboral o los

${ }^{1}$ Según el Libro blanco de los derechos de autor de las traducciones de libros en el ámbito digital publicado por ACE Traductores en 2016 un 28,2\% de los traductores se dedica en exclusiva a la traducción de libros. 
“Transfer” XV: 1-2 (2020), pp. 93-114. ISSN: 1886-554

ingresos. Y ochenta años más tarde, seguimos encontrándonos con una actividad (llamémosla así) que es precaria e inestable en todos sus aspectos: contractuales, laborales, económicos. No existe vínculo laboral con la editorial que encarga una traducción más allá del contrato firmado para cada libro concreto. No hay continuidad, seguridad social, puesto fijo o prestigio asociado. Los traductores de libros en España son freelance; no porque les guste ser libres y autónomos sino porque son "colaboradores externos". Según los datos publicados por la Federación de Gremios de Editores de España, en 2017 el 90,1\% de las editoriales recurrieron a personal externo y, en función del tamaño de la editorial, contrataron entre 10 y 247 colaboradores (traductores, correctores, ilustradores) (Comercio interior del libro en España 2017, 2018: 31), mano de obra de quita y pon que, en su conjunto, permite que se publique un total de unos 90000 títulos al año, un $21,1 \%$ de los cuales son traducciones (un 25,4 \% de los textos de creación literaria, un $35,4 \%$ de los libros de tiempo libre y un $47 \%$ de los títulos juveniles e infantiles (Panorámica de la edición española 2017, 2018: 6 y 46) Este considerable volumen de títulos traducidos (en torno a unos 19000 , cifra que aumentó en un $36,8 \%$ respecto al año anterior) explica y justifica que el planteamiento profesional de los traductores españoles sea muy distinto del que puedan tener los de países donde el volumen de obra traducida es mucho menor (sin ir muy lejos, véase el caso británico, que ha pasado del tradicional $3 \%$ a un discreto $5,5 \%{ }^{2}$ )

Así pues, en este sentido algo sí ha cambiado desde la época de Ortega y Gasset: el sector editorial español maneja actualmente unas cifras importantes y es uno de los más poderosos del mundo; según la mencionada Panorámica:

\footnotetext{
${ }^{2}$ En: $<<\underline{\text { https://bit.ly/2IUOLJ0 }>>~(F e c h a ~ d e ~ c o n s u l t a, ~} 18$ de marzo de 2019).
} 
“Transfer” XV: 1-2 (2020), pp. 93-114. ISSN: 1886-554

\begin{abstract}
Estos datos constatan que el sector del libro mantiene su solidez y posición, siendo la primera industria cultural en España, como apunta el Anuario de Estadísticas Culturales 2017, publicado por este Ministerio, que señala que el sector de libros y prensa aportó en 2015 el 0,8 \% del PIB total y el 33,7 \% del PIB del conjunto de actividades culturales. España es una de las grandes potencias editoriales del mundo y uno de los principales mercados europeos en cuanto a disponibilidad de títulos. A este respecto, según la Federación de Editores Europeos, España ocupa el quinto puesto detrás de Reino Unido, Alemania, Italia y Francia. (Panorámica de la edición española 2017, 2018: 6)
\end{abstract}

Y como estamos viendo, este crecimiento no es ajeno a la obra traducida. En este aspecto es fundamental el Informe del valor económico de la traducción editorial editado por ACE Traductores en 2017, que menciona una serie de puntos en sus conclusiones que podríamos resumir en dos: el papel de los traductores es clave en el engranaje de la industria editorial y, en segundo lugar, el peso de la traducción, si nos atenemos a la cifra de facturación de los libros traducidos, se elevaría hasta representar en torno a un 35\% del total. Con todo, y a pesar de lo dicho, se ha producido una pérdida de poder adquisitivo de los traductores editoriales por un incremento inferior de las tarifas de retribución que el del conjunto de los trabajadores, e incluso, de la inflación.

En conclusión, los casi 19000 títulos traducidos que se publicaron en 2017 suponen un peso importantísimo en la industria editorial; más todavía si nos atenemos a las cifras de ventas, puesto que la mitad de los libros preferidos de los lectores son traducciones, como lo son también la mitad de sus autores favoritos.(Hábitos de lectura y compra de libros en España 2018, 2019: 106).

\title{
Una ocupación precaria
}

A pesar de su importancia, la profesión del traductor de libros es insegura e inestable. Tal como dice en sus conclusiones el estudio 
“Transfer” XV: 1-2 (2020), pp. 93-114. ISSN: 1886-554

de ACE Traductores publicado en 2016:

Se mantiene la precarización de la profesión al no haber seguridad ni continuidad en el trabajo. Salvo un pequeño grupo, no hay profesionalización de los traductores. Se ha reducido de forma considerable el perfil de los traductores exclusivos, pasando de un $37,5 \%$ a un $28,2 \%$, y ha aumentado en consecuencia, en casi diez puntos, el porcentaje de los traductores con dedicación no exclusiva. Es plausible suponer que la crisis económica ha sido una de las causas de este cambio en los perfiles. (Libro blanco de los derechos de autor de los traductores de libros en el ámbito digital, 2016: 90)

No obstante su importancia, este tipo de actividad - faena, ocupación- se sigue sosteniendo en gran medida gracias a una forma de explotación que Remedios Zafra ha definido con clarividencia en El entusiasmo: Precariedad y trabajo creativo en la era digital:

El apoyo de la práctica creativa se materializa cada vez más en contextos competitivos que rompen los lazos de solidaridad entre iguales. Se sustentan además en trabajo pocas veces y escasamente remunerado que esquiva la contratación estable y se presenta bajo eufemísticas propuestas de formación, experiencia o prácticas. Es visible cómo el mundo cultural es mantenido por colaboradores a tiempo parcial, entusiastas becarios y figuras diversas para la gestión de redes (nombradas, a ser posible, en inglés y pagadas con audiencia y renglones de currículum). (Zafra 2017: 25)

Traducción editorial y precariedad han ido tradicionalmente de la mano: ${ }^{3}$ terreno abonado para que se acentúe el fenómeno de

\footnotetext{
${ }^{3}$ Es muy reveladora, en todos sus detalles, la anécdota que cuenta García Yebra en la conferencia "Relaciones entre editores y traductores" de 1968. A propósito de la falta de aprecio por la traducción por parte de no pocos editores, explica que tras el encargo de un libro, "hice mi trabajo lo mejor que pude, y en un plazo que difícilmente habría podido ser más breve. Pero mi 'amigo' [el editor], a la hora de manifestar de hecho su aprecio de mi labor, pretendió pagar mis horas de trabajo a menos de lo que pagaba mi mujer las de la interina que nos limpiaba el piso. Al manifestarle yo mi extrañeza, me contestó textualmente: ‘¿Quién te mandó emplear tantas horas?' Estas palabras demostraban (...) una carencia total de aprecio al
} 
“Transfer” XV: 1-2 (2020), pp. 93-114. ISSN: 1886-554

feminización profesional que estamos presenciando.

La práctica cultural se feminiza y nutre de un excedente de mujeres formadas en lo que aún llamamos ciencias sociales y humanidades (viejas y nuevas). Un excedente que conforma una bolsa de mujeres creativas desempleadas y precarizadas a las que pronto les salpica la abdicación de los poderes públicos en sus responsabilidades sociales relativas al cuidado y la atención a las personas dependientes. (Zafra 2017: 23)

El hecho de que un sector se feminice debería constituir por sí mismo una señal de alarma. Según diversos estudios, cuando las mujeres entran en áreas laborales consideradas tradicionalmente masculinas, estas pasan a tener un estatus inferior e incluso los sueldos se reducen. ${ }^{4}$ El modelo de superioridad masculina (BOSERUP 1970) sugiere que la entrada de mujeres en determinado sector devalúa el prestigio y las remuneraciones. De acuerdo con esta hipótesis, los dos efectos se refuerzan mutuamente; las mujeres entran en áreas de remuneraciones bajas y este hecho, a su vez, reduce los salarios.

\section{Feminización de la industria editorial}

La feminización de un sector productivo es un fenómeno complejo en el que interactúan múltiples causas. Intentaremos aquí esbozar algunas de ellas, si bien el análisis completo queda lejos de nuestras posibilidades inmediatas y sería deseable que lo abordara la propia industria del libro y lo estudiaran los organismos competentes involucrados (Cultura, Igualdad y Trabajo). Citando de nuevo las conclusiones del Informe de ACE Traductores 2017: "Publicar información más rica ayudaría a mejorar la transparencia del sector y favorecería el buen funcionamiento del mercado".

trabajo hecho con esmero". (García Yebra 1989: 376)

${ }^{4}$ Este fenómeno está especialmente estudiado en las profesiones sanitarias, que se han feminizado muy rápidamente en Europa en los últimos años. Véase VÁZQUEZ 2010: 49, 54 y 193 
“Transfer” XV: 1-2 (2020), pp. 93-114. ISSN: 1886-554

(Informe del valor económico de la traducción editorial, 2017: 51)

Pero la feminización es un proceso generalizado en todo el ámbito cultural: en España lo estamos presenciando en la cultura en casi todos los terrenos; si no tanto en la producción - ya que los hombres siguen siendo mayoría en los puestos de trabajo de las distintas industrias culturales (59,5\%, frente al 54,5\%) y son mayoría abrumadora como miembros de entidades de gestión de derechos de autor (el 23,2\% son mujeres y el 76,8\% restante hombres)-, sí, al menos en el consumo: las mujeres llenan los cines, teatros y museos; también compran y leen más libros (Anuario de estadísticas culturales 2017, 2017: 57 y 29). Al mismo tiempo, hace ya años que las mujeres son mayoría en las carreras universitarias que forman a gran parte de los traductores (Filologías y Estudios de Letras en general). Si el 54\% de los estudiantes universitarios de grado son mujeres, según el INE, los titulados en "Artes y Humanidades", que es el epígrafe generalista, son mujeres en un 65\%. ${ }^{5} \mathrm{Y}$ las tituladas en Traducción e Interpretación en las universidades públicas presenciales son un $80,7 \%$ del total. (La Universidad española en cifras, 2018: 63)

La industria editorial, por su parte, también está viviendo un proceso similar. Así lo expone un esclarecedor artículo de Manuel Rodríguez Rivero publicado en El País en 2011:

Mi generación asistió en directo y en muy poco tiempo al enorme cambio que supuso la incorporación masiva de la mujer al trabajo. En el mundo editorial, la avalancha de mujeres ha sido tan espectacular en los últimos 25 años que ha motivado que los comentaristas (la mayoría hombres) nos hayamos referido ampliamente a una presunta "feminización" de la edición, lo que implica un malentendido. Es verdad que uno entra en las grandes editoriales y ve mujeres por todas partes. Pero, como ya he explicado en alguna ocasión, no están repartidas por igual en todos los puestos y responsabilidades: su horizonte profesional permanece (casi) inamovible en el umbral del santuario en el que se toman las grandes decisiones, de modo

${ }^{5}$ Instituto Nacional de Estadística, disponible en $<<$ https://bit.ly/2YcwklV $>>$. En 2009-2010, por ejemplo, el INE daba un total de 1555 titulados en T\&I de los que 1290 eran mujeres (Fecha de consulta 18 de marzo de 2019).

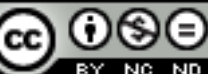


“Transfer” XV: 1-2 (2020), pp. 93-114. ISSN: 1886-554

que en las plantas nobles su presencia tiende a enrarecerse. (Rodríguez Rivero, El País, 16 de febrero 2011)

Seis años después del artículo de Rodríguez Rivero, el 49\% de los empleados en nómina de las empresas editoriales agremiadas son mujeres. Este porcentaje es significativamente mayor en las empresas grandes, ya que alcanza el 63\%, en tanto que en las pequeñas supone el 40,5\% del total de empleados.(Comercio interior del libro en España 2017, 2018: 30) Sin embargo, si se analiza el puesto de director, la proporción de mujeres se reduce considerablemente y es de 1 mujer por cada 2 hombres. ${ }^{6}$ Rodríguez Rivero prosigue analizando causas y motivos:

\begin{abstract}
Las razones de esa espectacular incorporación de las mujeres a la edición han sido muchas. Una importante fue que el ejército laboral empezó a poblarse de jóvenes universitarias bien preparadas que trabajaban con más ímpetu que sus colegas masculinos (tenían más que demostrar en un espacio acotado por ellos), hablaban idiomas y hacían gala de más mano izquierda para tratar con los autores, que son los que, en definitiva, suministran la materia prima del negocio. Pero también hubo otros motivos. A principios de los años noventa, cuando ya era un hecho evidente que las mujeres habían llegado a la edición para quedarse, el consejero delegado de la editorial en la que yo trabajaba me explicó que las contrataba porque resultaban "más baratas que los hombres y protestaban menos". De lo segundo nunca estuve demasiado seguro. Pero lo primero tenía mucho que ver con la enorme reticencia que este sector (en particular) ha mostrado a equiparar salario igual a trabajo igual. Como en este país no se publican nunca (al contrario que en otros) datos sobre el abanico salarial correspondiente a cada puesto de trabajo editorial, no hay manera de saber cómo han evolucionado los sueldos. Pero tengo la convicción de que, en conjunto, los grandes empresarios editoriales se ahorraron entonces un montón de dinero contratando a mujeres por salarios inferiores a los que pagaban a los hombres por el mismo trabajo. Una forma rezagada de
\end{abstract}

${ }^{6}$ Directorios, Federación de Gremios de Editores de España, disponible en $<<$ http://federacioneditores.org/directorio-resultado.php $>>$ (Fecha última consulta, 18 de marzo de 20199. 
“Transfer” XV: 1-2 (2020), pp. 93-114. ISSN: 1886-554

acumulación primitiva.

Afortunadamente, en las editoriales las cosas han ido cambiando en la dirección de la igualdad. Y mucho más profundamente que en otros eslabones de la cadena del libro. (Rodríguez Rivero, El País, 16 de febrero 2011).

\section{Un proceso en marcha: mujeres y traducción literaria}

Es una afirmación común que a lo largo de la historia la traducción ha sido una ocupación mayoritariamente femenina; ${ }^{7}$ no obstante, es difícil sustentarla con cifras concretas (al menos, en lo que respecta a la lengua española) y el mero repaso del índice onomástico de las obras de consulta más extensas de que disponemos (Pegenaute \& Lafarga 2004 y 2009) muestra una abrumadora mayoría de varones, no solo en tiempos pasados sino también a lo largo de todo el s. XX, lo que es, si no fiel reflejo de la historia, al menos un síntoma significativo de cuál es el relato de la profesión en relación con el sexo de los traductores.

Hasta la aparición de los estudios de ACE Traductores es escasísima la información sobre el perfil del traductor de libros. El primer Libro Blanco de la traducción en España, publicado en 1997, destaca que la distribución por sexo evidencia mayor presencia de hombres; un 58,5\%. No obstante, el Informe sobre la situación del traductor de libros en España, publicado en 2003 por ACE Traductores, señala ya lo siguiente:

Entre los noveles - hasta seis años de experiencia- las mujeres duplican con creces la representación porcentual de los hombres (38\% frente a 15\%) y asimismo es muy notable la sobrerrepresentación de los menores de treinta

\footnotetext{
${ }^{7}$ El hecho de que la traducción se conciba como actividad secundaria y marginal hace que se considere tradicionalmente como "femenina", y tal vez lo haya sido en el sentido que le daba Virginia Woolf: "I would venture to guess that Anon [Anonymous], who wrote so many poems without singing them, was often a woman", frase que se resume y traduce habitualmente como "Anónimo es nombre de mujer". (Woolf 1929).
} 
“Transfer” XV: 1-2 (2020), pp. 93-114. ISSN: 1886-554

y cinco años (80\% frente al 28,5\% del total). Por el contrario, en el grupo de los más veteranos -más de quince años de experiencia- la representación de los hombres casi duplica la de las mujeres (52\% frente a $27 \%$ ) y la de los traductores mayores de cincuenta y cinco años es también casi el doble que la del conjunto ( $71 \%$ frente a 38\%). A partir de estos datos creemos que puede hablarse en rigor de la existencia de un proceso de feminización de la profesión traductora, más allá del proceso general de incorporación de las mujeres al ámbito del mercado laboral en su conjunto. (Informe sobre la situación del traductor de libros en España, 2003: 14)

Esta tendencia se confirma en los Libros Blancos posteriores:

$$
\begin{array}{ll}
\text { - } & \text { Libro Blanco } 1997 \text { 41,5\% mujeres } \\
\text { - } & \text { Libro Blanco } 2010 \text { 54,1\% mujeres } \\
& \text { Libro Blanco } 201652,1 \% \text { mujeres }
\end{array}
$$

Y los datos por franjas de edad indican una marcada feminización en el relevo generacional:

\begin{tabular}{|l|c|c|}
\hline \multicolumn{2}{|l|}{ HOMBRE } & MUJER \\
\hline Base: total entrevistas & 282 & 332 \\
\hline Menos de 26 años & $0,7 \%$ & $1,2 \%$ \\
\hline De 26 a 35 años & $11,3 \%$ & $28,9 \%$ \\
\hline De 36 a 45 años & $32,6 \%$ & $27,4 \%$ \\
\hline De 46 a 55 años & $27,0 \%$ & $25,9 \%$ \\
\hline De 56 a 65 años & $19,9 \%$ & $13,9 \%$ \\
\hline Mayor de 65 años & $8,5 \%$ & $2,7 \%$ \\
\hline Media de edad & 48,6 & 43,9 \\
\hline
\end{tabular}

Tabla 1: Composición de la muestra del estudio del Libro Blanco (2010) por edades y sexo. (Libro Blanco 2010)

Se constata en la tabla que el rango de las traductoras de 26 a 35 años triplica el de los varones y es significativo el mayor peso de las mujeres entre los traductores con menos de 10 años de experiencia. A estos datos hay que sumar que es más acusada la feminización entre los profesionales que se dedican en exclusiva a 
“Transfer” XV: 1-2 (2020), pp. 93-114. ISSN: 1886-554

la traducción de libros. No obstante, hay que tener en cuenta que en las profesiones precarias y feminizadas las tasas de abandono son relativamente altas, por lo que no podemos extrapolar esos datos ni predecir el futuro inmediato de manera mecánica

Según el Libro Blanco 2016:

- $\quad$ el traductor en exclusiva es con mayor frecuencia mujer que hombre: $36,9 \%$ frente al $18,8 \%$.

- $\quad$ hay un mayor porcentaje de autónomos entre las mujeres: 55,7\% frente al $33,9 \%$.

- la variable sexo viene a inclinar un mayor peso de las mujeres entre los traductores frecuentes (de 3 a 5 libros anuales) o intensivos ( $>5)(62,2 \%$ y $58,8 \%$.

- $\quad$ un mayor peso de los hombres entre los esporádicos o moderados.

\section{Análisis detallado del encargo: escollos para la igualdad}

Desde el momento en que la editorial elige el libro que desea que se traduzca hasta que la obra llega a las manos del lector nos enfrentamos a una sucesión de pasos que implican, a su vez, una suma de decisiones, algunas de ellas significativas en lo que puede suponer el acrecentamiento de una brecha de género y cierta segregación vertical y horizontal. En este sentido, son relevantes los estudios sobre las dificultades añadidas que tienen las mujeres en las negociaciones de los contratos. ${ }^{8}$

\footnotetext{
8 "Un experimento sobre discriminación de género en el mercado de trabajo demuestra que las mujeres de entre 37 y 39 años tienen en promedio un 30\% menos de probabilidades de ser convocadas a una entrevista de trabajo que los hombres con sus mismas características. La discriminación de género es mayor en candidatas con hijos, y se reduce, aunque no desaparece por completo, cuando tienen mayor cualificación para el puesto". Sería interesante estudiar si la misma discriminación se produce en trabajos freelance. ¿Tienen las mujeres menos oportunidades de ser contratadas?, marzo 2019. Disponible en:

$<<$ https://observatoriosociallacaixa.org/es/>> (Fecha última consulta, 18 de marzo de 2019).
} 
“Transfer” XV: 1-2 (2020), pp. 93-114. ISSN: 1886-554

a) La editorial elige un traductor para la obra que desea publicar Este proceso de selección es ya un filtro digno de estudio al que pocas veces se le presta atención. En gran medida, porque los traductores que los Libros Blancos 2010 y 2016 denominan "esporádicos" - aquellos que solo traducen ocasionalmente, por lo general obras que ellos mismos eligen de acuerdo con su currículum o intereses $-{ }^{9}$ están sobrerrepresentados en la crítica (Fernández 2012) y en el mundo universitario, y suelen tomarse de manera equivocada como modelo del proceso.

Si nos atenemos al grueso de la producción, ahí donde la decisión de la editorial es determinante, sus criterios pueden implicar sesgos contrapuestos, pues la editorial podría decantarse por la elección de una mujer si esta ofrece menor conflictividad o acepta tarifas más bajas (tal como apuntaba Rodríguez Rivero y sugieren los estudios de ACE Traductores); al mismo tiempo, el hecho de que más mujeres se dediquen a la traducción en exclusiva implicaría mayor disponibilidad y celeridad en la entrega pero menor capacidad de negociación (por temor a perder un trabajo necesario o a las represalias futuras en caso de conflicto).

La traductora que firma estas líneas, con más de treinta años de experiencia con distintas editoriales, se atreve a apuntar otra hipótesis (sin restar por ello importancia a las mencionadas): las editoriales tienden a buscar un traductor "espejo" del autor, un profesional que sea en la medida de lo posible fiel reflejo en edad, sexo y circunstancias del creador original. Esta opción, si bien parece razonable en muchos sentidos, se sustenta en el deseo de invisibilidad del traductor y, además, reproduce de manera casi mecánica un sistema de valores concreto, así como el predominio del varón en la difusión de obras y géneros de mayor prestigio.

\footnotetext{
${ }^{9}$ Este tipo de traductor es por lo general varón (ACE Traductores 2003, Libro Blanco 2010 y 2016), traduce a partir de una sola lengua y compagina la traducción de libros con otra actividad profesional.
} 
“Transfer” XV: 1-2 (2020), pp. 93-114. ISSN: 1886-554

b) Negociación del contrato: tarifa, fechas, irregularidades

Tras la llamada o el correo electrónico del editor proponiendo la traducción de una obra, el siguiente paso es la negociación del contrato de traducción. Esta etapa supone sin duda una serie de obstáculos, derivados principalmente de que dista de ser una negociación entre iguales y, por lo general, la editorial presenta un contrato que el traductor puede aceptar o rechazar, pero del que pocas veces se atreve a negociar algo más que la fecha de entrega. Son pocos los contratos que cumplen con todos los requisitos establecidos en la Ley de Propiedad Intelectual (véanse los mencionados Libros Blancos) y, sin embargo, la capacidad de los traductores de sugerir $\mathrm{u}$ ofrecer algunos de los modelos de contrato pactados con la Federación de Gremios de Editores es manifiestamente escasa (ACE Traductores 2017).

Los estudios sobre el empleo femenino tienden a destacar que la negociación de los contratos es uno de los puntos delicados porque se pone de manifiesto cierta debilidad de las mujeres para exigir sus derechos o negociar condiciones ventajosas. Según un reciente informe de PWC para la CEOE:

Distintos estudios analizan los efectos de los distintos rasgos psicológicos y habilidades no cognitivas de hombres y mujeres sobre sus salarios y carreras profesionales. Según los mismos, mientras que las mujeres presentan ventajas en áreas como las relaciones interpersonales, los hombres parecen contar con una mayor propensión a asumir riesgos y a negociar y competir.

No obstante, ya en un estadio previo, el primer problema que se plantea (que evidencian todos los estudios de ACE Traductores) es la ausencia de contrato. Según ACE Traductores 2003:

En el grupo en disminución de quienes han traducido siempre sin establecer relación contractual con las editoriales, las mujeres han mantenido una sobre representación significativa que, no obstante, se ha ido moderando en los años sucesivos: en 1995-96 las mujeres superaban a los hombres en 14 puntos porcentuales y en 2001 sólo en 5 puntos. (....) Las mujeres y los menores de treinta y cinco años han trabajado siempre sin contrato en pro- 
“Transfer” XV: 1-2 (2020), pp. 93-114. ISSN: 1886-554

porción mayor que el resto. (Informe sobre la situación del traductor de libros en España 2003: 24 y 73)

Según el Libro Blanco 2016, el 28,2\% de los traductores hicieron su última traducción sin haber firmado ningún conrato. Comparando datos de 2009 con 2015 apenas hay diferencias significativas en esta cuestión, lo que parece indicar un enquistamiento en el incumplimiento ${ }^{10}$ de la Ley de Propiedad Intelectual.

En relación con uno de los aspectos fundamentales del contrato, la tarifa pactada en concepto de anticipo a cuenta de los derechos de autor por la traducción, la editorial suele establecerla en función de criterios propios en los que intervienen básicamente dos variables: la lengua original (su dificultad o la disponibilidad de profesionales que la dominen) y, en menor grado, la complejidad del texto (en este sentido, la literatura infantil y juvenil tiende a tener tarifas más bajas). La horquilla de negociación con el traductor suele ser muy escasa y es mayor la variación entre editoriales. ${ }^{11}$

En cuanto a la posible existencia de una brecha salarial, el Informe 2003 destacaba que los hombres, en conjunto, estaban mejor pagados; los valores medios de la tarifas de las mujeres y de los más jóvenes eran muy próximos, lo que se explicaba por la incorporación a la traducción de mujeres jóvenes. ${ }^{12}$ En los estudios posteriores no se observa diferencia en las tarifas por sexo (pero

\footnotetext{
${ }^{10}$ Según los datos del estudio del Instituto DYM para el Libro Blanco 2010 (inéditos), no se aprecian diferencias estadísticas entre hombres y mujeres en la ausencia de contrato.

${ }^{11}$ Datos inéditos procedentes de un estudio interno realizado por ACE Traductores sobre tarifas y contratos.

${ }^{12}$ Según el Libro Blanco 1997, la tarifa media de las mujeres era de 1.328 ptas. (7,98 $€)$ por página de 2.100 matrices y la de los hombres era de 1.482 ptas. $(8,58 €)$. No obstante, hay que señalar que la media de ingresos brutos anuales por traducciones de libros es mayor en las mujeres porque la actividad media también lo es (Libros Blancos 2010 y 2016).
} 
“Transfer” XV: 1-2 (2020), pp. 93-114. ISSN: 1886-554

es muy posible que las distintas variables que entran en juego al negociar la tarifa - grado de "exotismo" de la lengua original, dificultad del texto, género de la obra, disposición del editor a negociar, capacidad de negociar del traductor, urgencia en la entrega, porcentaje de derechos de autor- se compensen entre sí, por lo que sería necesario un análisis más detallado para llegar a conclusiones significativas.

Otro punto fundamental del contrato es el porcentaje de derechos de autor (tal como establece la Ley de Propiedad Intelectual en el Artículo 46: "La cesión otorgada por el autor a título oneroso le confiere una participación proporcional en los ingresos de la explotación, en la cuantía convenida con el cesionario") (Texto refundido de la Ley de Propiedad Intelectual, BOE-A-19968930). Según ACE Traductores 2003, la media del porcentaje de derechos de autor estipulado en los contratos aparece ligeramente más alta entre los hombres, entre los que tienen más de cincuenta y cinco años y los que llevan más de quince años traduciendo. Probablemente, se debe a una mayor capacidad de negociación y a que, además, traducen más clásicos (obras libres de derechos para las que suele establecerse mayor porcentaje).

\section{c) Aparición y resolución de conflictos}

Llegado el caso, es mayor el porcentaje de traductoras que presenta algún tipo de reclamación ante el editor; ${ }^{13}$ no obstante, resulta inquietante que en términos generales sean tantos los traductores y traductoras que consideren que no hay conflicto ni necesidad de negociación, ya que ese mismo Libro Blanco muestra un elevadísimo índice de irregularidades contractuales. En este sentido, tal vez el entusiasmo ayude a pasar por alto los aspectos negativos. ${ }^{14}$

\footnotetext{
${ }^{13}$ Datos inéditos del estudio del Instituto DYM para el Libro Blanco 2010.

${ }^{14}$ Es muy significativa la invención por parte de algún editor de un "contrato de prácticas" para la contratación de jóvenes sin experiencia con la finalidad de justificar tarifas ridículas.
} 
“Transfer” XV: 1-2 (2020), pp. 93-114. ISSN: 1886-554

\begin{abstract}
Llama la atención cómo empleos creativos y culturales hoy siguen un camino donde la ambigüedad ha sido empleada para difuminar su trabajo, bajo perversas formas de consideración que hacen borrosa su denominación y pago. Alimentar un sistema apoyado en el entusiasmo y en la suficiencia de un pago inmaterial es otro factor que nos resulta tristemente familiar. Bien promoviendo la resignación o bien sustentándose en la idealización de prácticas vocacionales, afectivas y altruistas, allí habita mucha precariedad feminizada, ese terrorífico mito de las mujeres que ya están pagadas con el "amor que reciben”. (Zafra 2017: 200)
\end{abstract}

\title{
d) Aceptación de la traducción e introducción de correcciones
}

Coherentemente con lo apuntado por Fruela Fernández en su estudio sobre las mujeres en el sector de la traducción editorial, las editoriales tienden a someter las correcciones al visto bueno del traductor con menor frecuencia si se trata de una mujer (mayoría en la respuesta "nunca" y "pocas veces"). ${ }^{15}$ Algunos editores consideran que es un mero trámite engorroso, pero olvidan que con ello están violando el derecho moral del traductor a la integridad de su obra, tal como establece la ley de propiedad intelectual vigente.

\section{e) El libro en la calle: visibilidad. Críticas y premios}

Fernández (2012) se ha planteado si esta presencia creciente de las mujeres en la traducción editorial se manifiesta en una mayor visibilidad -tanto en la crítica como en los premios de más prestigio - o si, por el contrario, las traductoras desaparecen tras una doble invisibilidad. Sus conclusiones son muy llamativas: las traducciones realizadas por hombres obtienen el $71,86 \%$ de las valoraciones de la crítica publicada en la prensa de mayor tirada en España, mientras que las hechas por mujeres suponen solo el 23,29\%; además, las valoraciones positivas y muy positivas a las traducciones de los hombres suponen un $83,12 \%$ de las valora-

\footnotetext{
${ }^{15}$ Datos inéditos del estudio del Instituto DYM para el Libro Blanco 2010.
}

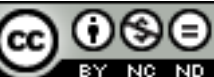


“Transfer” XV: 1-2 (2020), pp. 93-114. ISSN: 1886-554

ciones frente al $74,42 \%$ de las hechas por mujeres. Fernández concluye en su artículo que las mujeres, pese a su mayor presencia e implicación en la profesión, tienden a ocupar una posición subordinada, traducen obras y géneros menos formales y tienen menos presencia en lenguas centrales.

Citando de nuevo a Rodríguez Rivero:

\begin{abstract}
Sabemos que las mujeres leen y compran más títulos. Sabemos también que escriben mucho, aunque no sabemos cuántos libros publican. Entonces, ¿por qué se reseñan en los medios tantísimos más libros de autores que de autoras? ¿Y por qué la aplastante mayoría de los que firman esas críticas son varones? ¿Quizás porque en ese ámbito el techo de cristal todavía está demasiado cerca del suelo? En España no existe, que yo sepa, un seguimiento fiable de la relación de fuerzas (hombre / mujer) a la hora de orientar a los lectores desde los medios acerca de los libros que se publican. En otros sitios, sí. Les recomiendo, por ejemplo, la instructiva página vidaweb.org, en la que se exponen los resultados del "peinado" de algunos de los medios literarios de referencia en el mundo anglófono. Un par de ejemplos: en 2010 el Times Literary Supplement, publicó 1.036 reseñas de libros escritos por hombres y 330 por mujeres (las reseñas las firmaron 900 hombres y 341 mujeres), y en The New York Review of Books se publicaron 306 de hombres y 59 de mujeres (los autores de las reseñas fueron 200 hombres y 39 mujeres). No quiero ni pensar lo que aquí saldría si alguien hiciera el cálculo. A lo mejor se sonrojaban hasta los señores de la RAE, pongo por caso. (Rodríguez Rivero, El País, 16 de febrero 2011).
\end{abstract}

En cuanto al reconocimiento público, Fernández (2012) destaca que durante el periodo objeto de estudio también las mujeres fueron galardonadas con los premios nacionales de traducción en menor medida y que "la configuración profesional de los jurados tiende a reproducirse en los premiados": varones de cierta edad y con carreras profesionales académicas consolidadas.

Así pues, entre 1989 y 2009 solo un 12,5\% de mujeres recibieron el Premio a la Mejor Traducción y un 19,5\% a la Obra de un Traductor.

Un punto de inflexión fundamental, sin embargo, fue la Ley de Igualdad de marzo de 2007; como consecuencia de la cual, el

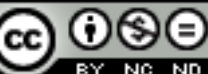


“Transfer” XV: 1-2 (2020), pp. 93-114. ISSN: 1886-554

Ministerio de Cultura se propuso establecer la paridad entre hombres y mujeres en la composición del jurado de los premios nacionales. A partir de ese momento se produce un cambio significativo y las premiadas en la categoría de la mejor Traducción son un $46 \%$ y en la Obra de un Traductor suponen un 42\%, datos que parecen reflejar en mayor medida la realidad de la traducción literaria. ${ }^{16}$

En contraste con los premios nacionales, es interesante señalar que el Premio de Traducción Esther Benítez que otorga ACE Traductores desde 2006 (con un jurado constituido por todos sus socios) ha sido concedido al mismo número de mujeres que de hombres.

Abundando en lo dicho por Fernández, los hombres traducen más obras de dominio público $(54,4 \%)$. Asimismo, reciben más ejemplares justificativos de las obras $\operatorname{traducidas}^{17}$ y sus traducciones suelen ser objeto de subvención con mayor frecuencia (lo que no siempre redunda en mejor tarifa, pero sí es indicativo del prestigio de la obra traducida) (Libro Blanco 1997).

En cuanto al lugar que ocupa el nombre del traductor en la obra publicada, ya sea en los créditos o la cubierta, parece necesario seguir investigando si, como decía ACE Traductores 2003, en mayor medida es el nombre de las mujeres el que desaparece de un lugar visible del libro.

\section{Conclusiones}

Las condiciones de precariedad inherentes al trabajo freelance, acentuadas por unas tarifas tradicionalmente bajas -que han

\footnotetext{
${ }^{16}$ En este sentido, cabe destacar que Eva Almazán, junto con tres personas más, ha sido Premio Nacional de Traducción en 2014 y Neila García Salgado lo ha recibido en la edición de 2018. Son las primeras premiadas formadas en una Facultad de Traducción (Vigo y Salamanca, respectivamente).

${ }^{17}$ Datos inéditos del estudio del Instituto DYM para el Libro Blanco 2010.
} 
“Transfer” XV: 1-2 (2020), pp. 93-114. ISSN: 1886-554

seguido bajando con la crisis reciente y no se han recuperado-y un alto grado de incumplimiento de la Ley de Propiedad Intelectual dificultan que esta actividad pueda abordarse con la profesionalidad que exigen la importancia de la industria editorial española y el volumen de obra traducida que se publica anualmente.

Al mismo tiempo, el proceso de feminización de la traducción literaria, que ya apuntaban el Libro Blanco de 1997 y el Informe de ACE Traductores en 2003, sigue avanzando, tal como confirman los estudios posteriores y resaltan los análisis por franjas de edad más recientes. Este dato en sí mismo debería ser una llamada de atención y un motivo de inquietud, ya que "Los varones son reticentes a entrar en mercados laborales con niveles de ingresos congelados, donde la autonomía profesional se resiente o donde los role models tienden a ser femeninos" (Rodríguez \& Bosch y Ramón 2010: 195-196).

Es sabido que en ausencia de regulación o convenios es el sector femenino el que más sufre las consecuencias, ${ }^{18}$ por lo que cada vez parece más necesario que se articule algún mecanismo legal - tal vez el futuro Estatuto del Artista permita acuerdos colectivos- que defienda unas condiciones de trabajo en las que los traductores y traductoras puedan desempeñar dignamente su labor.

Mientras tanto, la potente industria editorial española seguirá aprovechándose del entusiasmo de las jóvenes generaciones que acceden al mercado laboral - especialmente, las mujeres graduadas en Traducción e Interpretación-con mayor ilusión que expectativas reales de convertir esta humilde faena en una profesión.

\footnotetext{
${ }^{18}$ La negociación colectiva se ha identificado como reductora de la brecha salarial cuando su cobertura es amplia, y es uno de los factores institucionales más relevantes en la reducción de esta desigualdad. Instituto de la Mujer (2014).
} 
“Transfer” XV: 1-2 (2020), pp. 93-114. ISSN: 1886-554

\section{Referencias bibliográficas}

ACE TRADUCTORES. (1997). Libro blanco de la traducción en España, ACE Traductores, Madrid.

---. (2003). Informe sobre la situación del traductor de libros en España. En: <<https://bit.ly/2LtKjlQ >> [Descargado en marzo 2019].

---. (2010). Libro blanco de la traducción editorial en España, ACE Traductores, Madrid.

---. (2016). Libro blanco de los derechos de autor de las traducciones de libros en el ámbito digital, ACE Traductores, Madrid.

---. (2017). Informe del valor económico de la traducción editorial, Madrid.

BOSERUP, Ester. (1993), La mujer y el desarrollo económico, Minerva, Madrid.

CEOE-PRICEWATERHOUSE COOPERS. (2019). Análisis de la brecha salarial de género en España.

En: <<https://bit.ly/2WAaOq8 $>>$ [Descargado en marzo de 2019].

CRUE. (2018). La Universidad española en cifras, 2016-2017, Madrid.

En: $<<$ https://bit.ly/2H2RNqu $>>$. [Descargado en marzo de 2019]

FEDERACIÓN DE GREMIOS DE EDITORES DE ESPAÑA. (1918). Comercio interior del libro en España 2017. En: $<<$ https://bit.ly/2DTGu39 > . [Descargado en marzo 2019]

FEDERACIÓN DE GREMIOS DE EDITORES DE ESPAÑA. (1919). Hábitos de lectura y compra de libros en España 2018. En: $<<$ https://bit.ly/2DqBWBg $>>$. [Descargado en marzo 2019]

FERNÁNDEZ, Fruela. (2012). "De la profesionalización a la invisibilidad: las mujeres en el sector de la traducción editorial", TRANS, 16:49-64. 
“Transfer” XV: 1-2 (2020), pp. 93-114. ISSN: 1886-554

GARCÍA YEBRA, Valentín. (1983). "Relaciones entre editores y traductores". En: Entorno a la traducción, Gredos, Madrid, pp. 367-380.

INSTITUTO DE LA MUJER. (2014). Investigación conducente a la elaboración de un índice sintético de discriminación salarial. En: <<https://bit.ly/2PWFaRS $>>$. [Descargado en marzo de 2019]

LAFARGA, Francisco \& PEGENAUTE Luis. (eds.). (2004). Historia de la traducción en España, Salamanca: Ambos Mundos.

---. (2009). Diccionario histórico de la traducción en España, Madrid: Gredos.

ORTEGA Y GASSET, José. (1937). "Miseria y esplendor de la traducción”. En: El libro de las misiones, Madrid: Espasa Calpe, pp. 127-162.

RODRÍGUEZ DÍAZ, José Antonio.; BOSCH, José Luis C. \& RAMÓN ARIBAU, Anna, (2012). "Feminización de las profesiones sanitarias: una mirada sociológica". En: VÁZQUEZ VEGA, Pablo. (ed.). La feminización de las profesiones sanitarias, Madrid: Fundación BBVA, pp. 171-198.

RODRÍGUEZ RIVERO, Manuel. (2011). "De nuevo sobre damas y libros”, El País, 16 de febrero de 2011 Disponible en: $<<$ https://bit.ly/2vHuI7v $>>$. [Descargado en marzo de 2019]

MINISTERIO DE CULTURA Y DEPORTE. (2018). Panorámica de la edición española de libros 2017. Disponible en: $<<$ https://bit.ly/2H6PDHp $>>$. [Descargado en marzo 2019]

---. Anuario de estadísticas culturales 2017. Disponible en: $<<$ https://bit.ly/2WtkiE1 $>>$. [Descargado en marzo 2019].

WOOLF, Virginia. (1929). A Room of One's Own. Londres: Hogarth Press.

ZAFRA, Remedios. (2017). El entusiasmo: Precariedad y trabajo creativo en la era digital, Barcelona: Anagrama.

Fecha de recepción: 2.05.2019 Fecha de aceptación: 01.06.2019

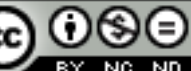


“Transfer” XV: 1-2 (2020), pp. 93-114. ISSN: 1886-554

\section{Resumen:}

Por causas diversas, en el mundo editorial español se está produciendo una feminización progresiva de la profesión de traductor literario. Analizados los datos por franjas de edad, se observa que en breve será mucho mayor la proporción de traductoras que la de traductores. En este sentido cabe preguntarse si esta feminización va acompañada de algún tipo de techo de cristal en relación con el prestigio de las obras traducidas, las tarifas o los ingresos. Y si, como resultado de lo dicho, las traductoras se ven sujetas a la doble invisibilidad derivada de la condición femenina y la inherente a una profesión considerada subalterna.

Palabras clave: Traducción literaria, Feminización, Techo de cristal, Invisibilidad, Sector editorial

THE FEMINIZATION OF THE PROFESSIONAL EXERCISE OF THE EDITORIAL TRANSLATION: BETWEEN PRECARITY AND ENTHUSIASM

\section{Abstract:}

A progressive feminization of the profession of literary translation is occurring in the Spanish editorial sector for several reasons. When analysing the age groups it is shown that the proportion of women translators is increasing and soon they will be a majority. In this context the question is whether this feminization is accompanied by some kind of glass ceiling barrier related to the prestige of the translated work, the rates or the total profits; and, as a result, women translators are subject to a double invisibility: the one derived from the fact of being a woman and the intrinsic 
“Transfer” XV: 1-2 (2020), pp. 93-114. ISSN: 1886-554

to a not highly regarded profession.

Keywords: Literary Translation, Feminization, Glass Ceiling, Invisibility, Publishing sector 